\title{
Assessing Groundwater Vulnerability Potential using Modified DRASTIC in Ajabshir Plain, NW of Iran
}

\author{
Asghar Ashari Moghaddam ( $\square$ Moghaddam@tabrizu.ac.ir) \\ University of Tabriz https://orcid.org/0000-0002-5984-094X
}

Sorayya Nouri sangarab

University of Tabriz

Ali Kadkhodaie Ilkhchi

Unversity of Tabriz

\section{Research Article}

Keywords: Ajabshir plain, DRASTICL, Groundwater vulnerability, Sugeno-type fuzzy logic

Posted Date: November 30th, 2021

DOI: https://doi.org/10.21203/rs.3.rs-1004866/v1

License: (c) (i) This work is licensed under a Creative Commons Attribution 4.0 International License.

Read Full License 


\section{Abstract}

The vulnerability of groundwater, as the primary source of water for human survival, should be assessed for the purpose of pollution management. The Ajabshir plain, one of the major agricultural areas in the northwest of Iran, is always prone to pollution. Therefore, to prevent the increase in pollution, it is necessary to determine the polluting factors and areas prone to groundwater pollution. In this study, by modifying the DRASTIC method using the land-use layer, called DRASTICL, vulnerable areas and pollution index were mapped. To ensure dealing with the uncertainty of the parameters, the DRASTICL model was optimized utilizing the Sugeno-type fuzzy inference system. The models were validated based on nitrate pollution. The correlation of DRASTICL and its optimized model with the nitrate pollution are 0.31 and 0.80 , respectively. The results of this study show that integrating the DRASTIC model and fuzzy knowledge is an instrumental way for assessment of vulnerability potential.

\section{Introduction}

Groundwater resources are important and reliable sources for agricultural, industrial and drinking purposes due to their biological and well- defined chemical properties and reservoirs. Furthermore, these resources are the vital source of water demands for more than half of the world's population. Groundwater, especially in agricultural and industrial areas, is more prone to pollution, and its scarcity is on a local and regional scale. From the early twentieth century, the use of chemical fertilizers in agricultural activities has been recognized as one of the major causes of groundwater pollution (Ascott et al., 2017). Physical, chemical, and biological pollutants mainly originate from human activities, and their abnormal concentration causes a gradual change in natural water quality (Asghari Moghaddam., 2010). Among the harmful pollutants in the human food chain, the nitrate anion $\left(\mathrm{No}_{3}{ }^{-}\right)$has been considered the main pollutant globally (Busico et al., 2020). Increased nitrate levels in groundwater can be due to sewage sludge disposal and agricultural activities. The impacts of groundwater pollution are remarkable in rural communities of developing countries that rely on untreated groundwater (Tuinhof et al., 2011). One of the reliable methods to prevent groundwater pollution is to identify its sources and vulnerable areas by preparing vulnerability maps and adopting appropriate management policies (Babiker et al., 2005).

There are several definitions of vulnerability, such as definition of 1993 U.S. National Committee on Groundwater Vulnerability to Pollution: the tendency or likelihood of contaminants reaching a specific location in the groundwater system, after their formation in some neighborhoods above the aquifer (Almasri, 2008). Identifying areas with a high potential for vulnerability will make it possible to control their contamination by taking the necessary measures (Asghari Moghaddam et al., 2009). Groundwater vulnerability map is based on the fact that in some areas, the potential for vulnerability to pollution is higher compared to the other sites (Piscopo, 2001). The concept of vulnerability was first introduced in France in the late 1960s to raise awareness about groundwater pollution (Vrba et al., 1995). The term vulnerability is conceptually considered in hydrogeology as intrinsic vulnerability and special vulnerability (Almasri, 2008; Gogu et al., 2000). The intrinsic vulnerability refers to the possibility of contamination in 
an area without considering specific pollutants (Almasri, 2008), while special vulnerability considers the vulnerability of groundwater to either a specific or group of pollutants, which depends on the characteristics of the pollutant and its relationships with various components of inherent vulnerability (Gogu et al., 2000). The term groundwater pollution potential was first used by Margat in 1968 (Bhuvaneswaran et al., 2019).

To qualitatively protect groundwater resources, investigating the potential of aquifer vulnerability to contamination can be an appropriate method. Vulnerability assessment methods include statistical, simulation-based and index-overlap methods (Almasri, 2008). Index-overlap methods include DRASTIC (Aller et al., 1987), AVI (Stempvoort et al., 1993), GODS (Foster et al., 1987) and SINTACS (Civita, 1994). The main difference among these methods is in the rating, number and the type of parameters. Barbulescu (2020) Reviewed DRASTIC and DRASTIC-like methods introduced by different scientists. These methods include DRASTIC (Aller et al., 1987), DRASTICM (Mendoza et al., 2006), DRIST (Chenini et al., 2015), DRAV (Zhou et al., 2010), DRAMIC (Wang et al., 2007), DRASTICA (Singh et al., 2015; Amadi et al., 2014), DRASTIC-LU (Alam et al., 2012), DRASIC-LU (Khan et al., 2010), SI ( Ribeiro,. 2000), DRACH (Qinghai et al., 2007) and SINTACS (Civita., 1994). The results shows the groundwater vulnerability maps are important tools for assessing the groundwater vulnerability and planning future land use. The reliability of the methods depends on the aquifer characteristics, the land use, the data availability, and the parameters involved in the model, the weightings, and rating assigned to each parameter. The DRASTIC framework is one of the most important index-overlap methods for determining the potential of vulnerability and pollution. First proposed in 1987 to assess the vulnerability of U.S. groundwater based on the concept of hydrogeological status, such framework is an experimental model (Aller et al., 1987). Several parameters such as land-use layer (Secunda et al., 1998; McLay et al., 2001) and population (Singh et al., 2015) have been used to modify the DRASTIC framework. However, due to the application of expert opinions in determining the weight of the parameters to ensure and eliminate uncertainty in the obtained result, it is necessary to use some weight improvement methods. In this regard, artificial neural networks, catastrophe theory, fuzzy logic and Wilcoxon have been used to optimize the DRASTIC method (Rezaei et al., 2013; Baghapour et al., 2016; Nadiri et al., 2018; Sadeghfam et al., 2015).

Many researches have used vulnerability potential identification methods and frameworks, some of which are reviewed below. Asghari Moghadam et al. (2016) used the DRASTIC and SINTACS methods to assess the vulnerability of the Bostanabad aquifer. The correlation coefficient of the results of DRASTIC and SINTACS with the nitrate layer was 0.75 and 0.58, respectively. Agossou and Yang (2021) used groundwater vulnerability to contamination methods for the Benin South Coast sedimentary basin. DRASTIC, the modified DRASTIC with land-use layer (DRASTICL), and AVI frameworks were used in their study. The results showed that the amount of correlation with nitrate increased by adding the land-use layer to the normal DRASTIC, i.e., the DRASTICL model. DRASTICL showed the highest correlation among all the methods used in the study. Jia et al. (2019) optimized the DRASTIC method by replacing the original parameters of aquifer media, soil media, the impact of the vadose zone, and hydraulic conductivity with quantitative parameters of aquifer thickness, nitrate attenuation intensity, hydraulic resistance, and groundwater velocity, as well as adding pollutant input intensity. They presented a new 
method called DRANTHVP, resulting in an increase in the correlation from 0.204 to 0.720 . Barzegar et al. (2014) optimized the DRASTIC model to assess the vulnerability of the Tabriz plain aquifer using Sugeno, Mamdani, and Larsen fuzzy methods and reported the acceptable performance of the Sugeno-type fuzzy method. According to their optimized model, the eastern regions of the city of Tabriz have the highest potential for pollution. Nadiri et al. (2017) used Sugeno, Mamdani, and Larsen fuzzy methods to improve the vulnerability index obtained from the DRASTIC method in the Ardabil plain. The results showed the high correlation of the model with the nitrate pollution using fuzzy logic methods.

In this study, to assess the vulnerability of the Ajabshir plain, the DRASTIC method modified with land-use layer, called DRASTICL, was used. Afterwards, the resulting vulnerability index was improved using the Sugeno-type fuzzy logic method.

\section{Materials And Methods}

\section{Study area description}

The Ajabshir plain basin, as a sub-basin of Urmia Lake, is located in the west of East Azarbaijan province and the catchment area of the Urmia Lake. The Ajabshir plain area is about 96 Square kilometers located on the south eastern shore of Urmia Lake. According to the Bonab meteorological station information, the mean annual temperature in the area is $13.64^{\circ} \mathrm{C}$ and the long-term mean annual precipitation is $252 \mathrm{~mm}$. The climate of the area is defined as cold semi-arid. The Qala-e-Chay River is the only surface water resources of the area which is originated from the Eastern highlands of Sahand Mountains discharging to the Urmia Lake. The altitude of the highest and lowest points of the region is 3357 and 1273 meters above msl, respectively. The digital elevation model and location of the study area is shown in Figure 1.

\section{Geology of the study area}

Ajabshir area has a considerable variety of geological formations outcrops. Extensive rock outcrops and sedimentary layers in the study area indicate a complex and long geological history. Published geological and tectonic maps show that Azerbaijan, including the study area, is the site of the Alborz and Zagros sedimentary-tectonic collisions and, finally, the Urmia Dokhtar volcanic zone (Darvishzadeh, 2001). Units belonging to the Upper Cretaceous period are extensive in the northwestern, northern, and northeastern parts of the plain. The Plio-Pleistocene volcanic tuffs have an extended exposure and overlie the Pliocene beds to the North east of the plain in the western part of the core of the Sahand volcano. Miocene units have a significant spread in the eastern highlands of the region (Darvishzadeh, 2001). The youngest sedimentary deposits are the recent sediments deposited in the Qala-e-Chay River channel, consisting of sand and gravel and to some extent, silt and clay. In the Ajabshir area, the Cretaceous outcrops in the northwest region are strongly folded and faulted, covered by the plain sediments in most areas. The general trend of folds and faults is northwest-southeast. There are many faults and fractures in this area, some of which are active and have affected Quaternary sediments. Also, the effects of the Sahand volcano and the spread of igneous rocks in the region on a large scale are other significant factors in this formation (Figure 2). 


\section{Hydrogeological setting}

The Ajabshir aquifer is an unconfined aquifer formed from the alluvial deposits. A part of this alluvium is formed by transporting the pyroclastic rocks of Sahand Mountains by the Qala-e-Chay River. It is made up of igneous rocks in the eastern part of the region, adjacent to the outcrops among Goltapeh, Gouran and Shiraz villages, to the north of Nansa, clay in the northern and northeastern parts and granular sediments from the middle part to the southwest. According to the reports of the Regional Water Corporation of East Azerbaijan Province, there are 622 active wells in the Ajabshir plain aquifer, mainly used for drinking and agricultural purposes, most of them are shallow wells, while a small percentage of which are deeply dug. There are 20 springs in the study area within the northeastern heights, and eight active Qantas are located in the study area (Figure 3).

\section{Modified DRASTIC with a land-use layer (DRASTICL)}

DRASTIC is one of the frameworks of the overlap-weighting method for assessing the potential of groundwater vulnerability to pollution. This framework includes seven parameters of groundwater depth to water $(D)$, net recharge $(R)$, aquifer media $(A)$, soil media (S), topography $(T)$, the impact of the Vadose zone (I) and hydraulic conductivity (C) of aquifer. The parameters are first rated and then weighted and overlapped in the GIS environment using the table presented by Aller (1987) (Table 1). Modified DRASTIC with land-use layer (DRASTICL) is the same as DRASTIC, except for adding the land-use layer parameter $(\mathrm{L})$ to the existing parameters. Therefore, Eq. (1) shows the formula for calculating the vulnerability index:

DRSASTICL $_{\text {Index }}=\mathrm{D}_{r} \mathrm{D}_{w}+\mathrm{R}_{r} \mathrm{R}_{w}+\mathrm{A}_{r} \mathrm{~A}_{w}+\mathrm{S}_{r} \mathrm{~S}_{w}+\mathrm{T}_{r} \mathrm{~T}_{w}+\mathrm{I}_{r} \mathrm{I}_{w}+\mathrm{C}_{r} \mathrm{C}_{w}+\mathrm{L}_{r} \mathrm{~L}_{w}$

Where the capital letters indicate the parameters used. The indices $r$ and $w$ represent the rate and weight of the parameters, respectively. The value of 10 is given to the highest vulnerability potential, while the value of 1 is given to the lowest vulnerability potential (Table 1). The weight of the parameters is between 1 and 5 , according to Table 1 . In this study, a weight of 5 is considered for the land-use layer.

Table 1. Rate and weight of the DRASTICL parameters (Aller, 1987) 


\begin{tabular}{|c|c|c|c|c|c|c|c|}
\hline \multicolumn{2}{|c|}{ Depth to water (5) } & \multicolumn{2}{|l|}{ Net recharge (4) } & \multicolumn{2}{|c|}{ Aquifer media (3) } & \multicolumn{2}{|l|}{ Soil media (2) } \\
\hline $\begin{array}{l}\text { Range } \\
(\mathrm{m})\end{array}$ & Rating & Range (mm) & Rating & Type & Rating & Type & Rating \\
\hline $0-1.5$ & 10 & $0-50.8$ & 1 & $\begin{array}{l}\text { Sandy- } \\
\text { Clay/Silt }\end{array}$ & 3 & Silty-loam & 4 \\
\hline $1.5-4.6$ & 9 & $50.8-101.6$ & 3 & $\begin{array}{l}\text { Clay/Silty- } \\
\text { Sand }\end{array}$ & 5 & Gravel-loam & 6 \\
\hline $4.6-9.1$ & 7 & $101.6-177.8$ & 6 & Sand/Gravel & 8 & & \\
\hline $\begin{array}{l}9.1- \\
15.2\end{array}$ & 5 & $177.8-254$ & 8 & & & & \\
\hline $\begin{array}{l}15.2- \\
22.9\end{array}$ & 3 & $254<$ & 9 & & & & \\
\hline $\begin{array}{l}22.9- \\
30.5\end{array}$ & 2 & & & & & & \\
\hline $30.5<$ & 1 & & & & & & \\
\hline \multicolumn{2}{|c|}{ Topography (1) } & \multicolumn{2}{|c|}{$\begin{array}{l}\text { Impact of the Vadose zone } \\
(5)\end{array}$} & \multicolumn{2}{|c|}{$\begin{array}{l}\text { Hydraulic conductivity } \\
\text { (3) }\end{array}$} & \multicolumn{2}{|l|}{ Land use (5) } \\
\hline $\begin{array}{l}\text { Slope } \\
(\%)\end{array}$ & Rating & Type & Rating & Range $(\mathrm{m} / \mathrm{d})$ & Rating & Type & Rating \\
\hline $0-2$ & 10 & Clay/Silt & 2 & $4>$ & 1 & $\begin{array}{l}\text { Natural } \\
\text { areas }\end{array}$ & 2 \\
\hline $2-6$ & 9 & Sandy-Clay/Silt & 4 & $4-12$ & 2 & $\begin{array}{l}\text { Pasture } \\
\text { areas }\end{array}$ & 4 \\
\hline $6-12$ & 5 & Clay/Silty-Sand & 6 & $12-18$ & 4 & $\begin{array}{l}\text { Artificial } \\
\text { areas }\end{array}$ & 8 \\
\hline $12-18$ & 3 & Sand/Gravel & 8 & & & $\begin{array}{l}\text { Farming } \\
\text { areas }\end{array}$ & 10 \\
\hline
\end{tabular}

$18<\quad 1$

\section{Model optimization using fuzzy logic}

Fuzzy logic replaces the need for a sophisticated and advanced mathematics system for design and modeling with linguistic quantities and expert knowledge. In other words, it is a kind of logic that uses the inference methods of the human brain. The concept of fuzzy logic was first introduced by Zadeh (1965). He argued that humans do not need precise information about inputs, but can design models that provide reliable responses by receiving incomplete data. The basis of fuzzy logic is based on fuzzy sets that extend the classical theory of sets in mathematics and offer membership functions. In this way, an individual is, to some extent, not entirely, a member of a set. In this theory, the membership of the members of a set is determined by the function $X(u)$, where $X$ represents a definite member and $u$ is a 
fuzzy function that determines the degree of membership of $X$ in the corresponding set, having a value between 0 and 1 (Eq. 2).

$$
A=\{(X . u A(x)) \mid x \in X\}, \mathrm{X}(0,1)
$$

In other words, $X(u)$ forms a mapping from the values of $x$ to possible numerical values between 0 and 1 . The function $X(u)$ might be a set of discrete or continuous values. When $u$ forms only some values between 0 and 1, it is discrete, but if it is constant, it creates a constant curve of decimal numbers in this range. Membership functions are used to consider the degree of membership, which include triangular, trapezoidal, Gaussian, bilateral Gaussian, point, L-shaped, S-shaped and sigmoid (Rajasekaran et al., 2005). For modeling with fuzzy logic, first, the input data should be represented as membership functions, and then, using fuzzy rules, the membership functions are linked to the output data. Fuzzy logic is implemented through practices called fuzzy operators, which are based on the IF-THEN rules. Fuzzy logic consists of three methods, Larsen, Mamdani and Sugeno, where the latter is usually used mainly due to the fixed and linear modeling process (Sugeno et al., 1985). This method of modeling consists of three steps: determining the structure or clustering, using fuzzy operators and estimating parameters and minimum squares of error. The research flowchart used in this study is shown in Figure 4. The vulnerability index was first modified with Eq. (3) to optimize the DRASTICL index by fuzzy logic, which is one of the methods of artificial intelligence

$$
\mathrm{Vul}_{i}=\frac{\mathrm{Vul}_{\max }}{\left(\mathrm{NO}_{3}\right)_{\max }} \times\left(\mathrm{NO}_{3}\right)_{\mathrm{i}}
$$

where $\mathrm{Vul}_{i}$ indicates the correction of the vulnerability index (DRASTICL index), $\mathrm{VuI}_{\text {max }}$ is the maximum value of the DRASTICL index, $\left(\mathrm{No}_{3}^{-}\right)_{\text {max }}$ is the maximum nitrate concentration, and $\left(\mathrm{No}_{3}^{-}\right)_{\mathrm{i}}$ is the nitrate concentration.

Fuzzy sets with vague and gradual boundaries between defined boundaries are an appropriate method to deal with human error and the nature of uncertainty in the system (Calvo et al., 2009; Tayfur et al., 2014). For this reason, in this study, the Sugeno-type fuzzy method was used to optimize DRASTICL relative to the nitrate concentration to assess the vulnerability of an area.

\section{Data normalization}

Eq. (4) was used to perform the data normalization process that eliminates the various ranges of data values by converting their values between 0 and 1

$$
X_{i}^{n}=\frac{X_{i-} X_{\min }}{X_{\max }-X_{\min }}
$$

where $X_{i}$ is the $i$-th data, $X_{\min }$ and $X_{\max }$ are the minimum and maximum data values, and $X_{i}^{n}$ is the normalized value of $X_{i}$. 


\section{Model implementation}

\section{Mapping the input layers of the DRASTICL framework}

To prepare the vulnerability map using DRASTICL, first, the information related to each of the parameters was collected and interpolated in the ArcGIS software environment and then rated and weighted according to the Aller standard (Aller, 1987). The method of preparing the map of each parameter is summarized below.

1. Groundwater depth (D) determines the depth of pollution infiltration to reach the water table. As groundwater depth increases, it takes longer for pollution to reach groundwater. Therefore, for lower depths, a rate of 10 is given, and for greater depths, the rate 1 is given. The groundwater depth layer was prepared after interpolation and rating according to Table 1 (Figure 5a).

2. Net recharge (R) indicates the amount of water infiltrated from the ground to the groundwater level. Water causes the contaminant to be transported vertically to the watertable. The Piscopo method (Piscopo, 2001) was used to create this layer. The effective parameters in this method are three layers of precipitation, soil permeability, and slope percentage (Table 2). By rating and overlapping these three layers, the net recharge layer was calculated according to Eq. (5) (Figure 5b).

Net Recharge index $=$ slope + precipitation + soil permeability

3. To prepare the layers of aquifer media (A), soil media (S), and impact of the Vadose zone (I), the material data of 25 logs in the area were used. Then, the rating was performed according to Table 1 so that the highest rate was assigned to coarse-grained sediments, while the lowest rate was assigned to fine-grained sediments, followed by the interpolation of the layers (Figures $5 c, 5 d$, and $5 e$ ).

4. Topographic layer $(T)$ indicates changes in the slope of the earth's surface. Increasing the topographic slope reduces the water retention on the ground and reduces the infiltration rate. Therefore, areas with a lower slope will be rated higher. The digital elevation model (DEM) of the region was used to prepare this layer, and then the rating was performed (Figure $5 f$ ).

5. Hydraulic conductivity (C) determines the permeability of the aquifer or the ability of the aquifer materials to transfer water. Therefore, the higher the hydraulic conductivity of the aquifer, the greater the possibility of contaminants flowing into the aquifer, which was obtained after introducing and rating the layer (Figure 5g).

6. Preparation of land-use layer $(\mathrm{L})$. Landsat images and soft ENVI software were used to prepare the land-use map. This map, which includes farming areas, residential and industrial areas, pastures and barren, was obtained as a raster layer and was rated in the ArcGIS environment. Figure 5(h) shows the land-use layer map. The highest rate is given to the most vulnerable area of the plain, which is farming areas, while the lowest rate is assigned to barren areas. It should be noted that the vulnerability of the residential and industrial areas is considered at an average level in this study. 
Table 2. Piscopo ratting (Piscopo, 2001)

\begin{tabular}{llllllll}
\multicolumn{2}{l}{ Net recharge } & \multicolumn{2}{l}{ Soil permeability } & \multicolumn{2}{l}{ Slope } & \multicolumn{2}{l}{ Precipitation } \\
\hline range & rate & range & rate & Slope $(\%)$ & rate & Rain $(\mathrm{mm})$ & rate \\
\hline $11-13$ & 10 & high & 5 & $2>$ & 4 & $850<$ & 4 \\
$9-11$ & 8 & Medium-high & 4 & $2-10$ & 3 & $850-700$ & 3 \\
$7-9$ & 5 & Medium & 3 & $10-33$ & 2 & $700-500$ & 2 \\
$5-7$ & 3 & low & 2 & $33<$ & 1 & $500>$ & 1 \\
$3-5$ & 1 & Very low & 1 & & & &
\end{tabular}

\section{Vulnerability index by the DRASTICL method}

After preparing and rating the parameters, the layers created in GIS were combined and overlapped using the weighted sum by applying their weights to obtain the DRASTICL framework index. The vulnerability index ranged from 117 to 185 in this study. Its value is divided into three categories: low (117-119), medium (120-115), and high (185-160) (Table 3). Due to the DRASTICL zoning map (Figure 7a), farming areas have the most significant potential for vulnerability. Moreover, the central regions of the plain have the highest vulnerability index.

Table 3. The DRASTICL framework index

\begin{tabular}{llll} 
Percentage of Area (\%) & Area $\left(\mathrm{km}^{2}\right)$ & DRASTICL range & Vulnerability range \\
\hline 30 & 28.8 & $117-119$ & Low \\
\hline 66.8 & 64.2 & $120-159$ & Medium \\
\hline 3.2 & 3 & $160-185$ & High
\end{tabular}

\section{Optimization of vulnerability mapping using fuzzy logic}

In this study, the Sugeno-type fuzzy logic was employed to optimize the DRASTICL model. The inputs of the fuzzy model were the eight main parameters of the DRASTICL framework and its output was calculated through Eq. (3). Afterwards, the values of all inputs and outputs of the layers were normalized using Eq. (4). A total of $80 \%$ of the data were considered training data, while the rest was used for the test. The reduction clustering method was used to classify the data, and the fuzzy model was implemented. $\mathrm{R}^{2}$ and RMSE, as performance evaluation criteria, were calculated for the prediction of training and testing data as 0.898 and 0.3 , respectively. Finally, with the interpolation of output data in GIS software, the DRASTICL map was improved with fuzzy logic, and a vulnerability index of 0.01 to 0.6 was obtained (Figure 7, b). The correlation coefficient between the outputs of the fuzzy logic method and the nitrate was 0.8 . The results of fuzzy logic optimization performance evaluation (Sugeno) are presented in Table 4. 
Table 4. The results of fuzzy logic optimization performance evaluation (Sugeno)

\begin{tabular}{ll} 
Evaluation criteria & $\mathrm{R}^{2}$ \\
\hline Training data & 1 \\
\hline Testing data & 0.898
\end{tabular}

\section{Discussion And Results}

The DRASTICL framework was used to determine the vulnerability potential of the study area. The DRASTICL index ranged from 117 to 185 . Based on the Aller classification, the index was divided into three categories of low, medium and high vulnerability (Table 3). Afterwards, nitrate pollution was used for corrected static validation, that was obtained by analyzing 26 water samples taken from active wells in the Ajabshir plain with evenly distribution. Since nitrate pollution has a human-made origin and can enter groundwater directly from the earth's surface, it is a suitable indicator for verifying groundwater vulnerability for pollution. Nitrate is considered a serious threat to the quality of groundwater resources due to the use of chemical fertilizers in agriculture. This pollutant has a more remarkable distribution compared to the other pollutants in the plain. Given the essential role for the groundwater in the drinking and health of the region populations, its entry into the human food chain can cause many problems. Therefore, there is a need for detailed studies on the factors that increase nitrate pollution in the region's groundwater. According to the interpolated map of nitrate concentration (Figure 6), its amount is at its highest in the north and northwest of the plain, including agricultural and industrial areas according to the land-use map. The correlation coefficient of the DRASTICL index with nitrate pollution was 0.31 . The correlation was taken between nitrate and the DRASTICL parameters which hydraulic conductivity, soil environment, and net nutrition play the most important roles in the vulnerability, and other parameters are less or balanced. The fuzzy logic method for optimization has been used for the uncertainty and disadvantages of expert opinions in determining the rate and weight of parameters. The value of the vulnerability index by the fuzzy logic method was also 0.01 to 0.6 falling in the safe zone in terms of vulnerability. The correlation coefficient of fuzzy logic results with nitrate was 0.8 . To ensure the accuracy of the methods performed, the correlation index (Cl) was obtained for both methods. According to the results presented in Table 5, the improved correctness with fuzzy logic has a higher correlation index (Table 4). Based on the results obtained from the correlation coefficient and correlation index obtained from the methods used with nitrate, it can be concluded that the optimized DRASTICL type with fuzzy logic is a better and more appropriate method for assessing the vulnerability of the Ajabshir plain. (Figure $7 a$ and $b)$.

Table 5. DRASTICL and DRASTICL - FUZZY correlation index $(\mathrm{Cl})$ and the correlation coefficient $\left(\mathrm{R}^{2}\right)$ 


\begin{tabular}{lcl}
$\mathrm{R}^{2}$ & $\mathrm{Cl}$ & Vulnerability methods \\
\hline 0.31 & 71 & DRASTICL \\
\hline 0.8 & 75 & DRASTICL - FUZZY
\end{tabular}

\section{Conclusion}

Most of the Ajabshir plain area is composed of farming areas. Due to this, with the intensive use of chemical fertilizers in agriculture and the growth of industry, groundwater has been exposed to the nitrate contamination. Therefore, to investigate the pollution of groundwater resources in the region, first, the vulnerability index was calculated by using the modified approach with eight effective parameters in pollution followed by Sugeno fuzzy logic optimization. The hydraulic conductivity and soil environment were very important in determining vulnerability indices and had a higher correlation coefficient compared to the other parameters involved in vulnerability index zoning. In the DRASTIC framework modified with the land use layer, the vulnerability index of 117 to 185 was in the range of low, medium, and high vulnerability, respectively. North and northwestern parts of the plain have a high vulnerability index. The central areas of the plain, which are mainly farming lands, have the highest vulnerability index. The optimized DRASTICL index with fuzzy logic was obtained from 0.01 to 0.6 , which is in the invulnerable range according to the Aller classification. The fuzzy logic method showed a satisfactory correlation and agreement with the nitrate concentration. The modified correlation coefficients of the DRASTICL and DRASTICL-fuzzy methods with nitrate concentration were 0.316 and 0.8 , respectively.

\section{Declarations}

-Ethical Approval:

\section{Not applicable}

-Consent to Participate:

Not applicable

-Consent to Publish:

I would like to submit the manuscript to be considered for publication as an original article in the Journal of Environmental Science and pollution research

-Authors Contributions:

Asghar Asghari Moghaddam: Supervision, Writing - original draft, Writing - review \& editing, Investigation, Methodology, Doing field works and Collecting water samples, analyzing water samples in laboratory; Sorayya Nouri Sangarab: Writing - original draft, Writing - review \& editing, Methodology, Software, Doing 
field works and collecting water samples, analyzing water samples in laboratory; Ali Kadkhodaie llkhchi: Writing - review \& editing, Methodology

-Funding:

No funding for this study

-Competing Interests:

The authors declare that they have no known competing financial interests or personal relationships that could have appeared to influence the work reported in this paper.

-Availability of data and materials:

Some of the basic data that support the findings of this study are openly available in East Azarbijan Regional Water Authority and some of them were directly collected by the Authors

\section{References}

Agossou, A. Yang, J. 2021. Comparative study of groundwater vulnerability to contamination assessment methods applied to the southern coastal sedimentary basin of Benin. Journal of Hydrology. 35; 100803.

Alam, F. Umar, R. Ahmad, S. Dar, A.F. 2012. A new model (DRASTIC-LU) for evaluating groundwater vulnerability in parts of Central Ganga plain, India. Arab. J. Geosci. 7: 927-937.

Aller, L. Bennett, T. Lehr, J. Petty, R. 1987. DRASTIC: a standardized system for evaluating groundwater pollution using hydrogeologic settings. US EPA, Robert S. Kerr Environmental Research Laboratory. 85(2): 35 .

Almasri, M.N. 2008. Assessment of intrinsic vulnerability to contamination for Gaza coastal aquifer. Journal of Environmental Management. 88(4): 577-593.

Amadi, N. Olasehinde, P.I. Nwankwoala, H.O. Dan-Hassan, M.A. Okoye, N.O. 2014. Aquifer vulnerability studies using DRASTICA Model. Int. J. Eng. Sci. Invent. 3: 1-10.

Ascott, M.J. Gooddy, D.C. Wang, L. Stuart, M.E. Lewis, M.A. Ward, R.S. Binley, A.M. 2017. Global patterns of nitrate storage in the vadose zone. Nat. Commun. 8 (1): 1416.

Asghari Moghadam, A. Nadiri, A. Paknia. 2016. Vulnerability assessment of Bostan Abad plain aquifer using DRASTIC and SINTACS methods. Journal of Hydrogeomorphology. 8: 21-52. [In Persian]

Asghari Moghaddam, A. Fijani, A. Nadiri, A. 2009. Groundwater Vulnerability Assessment of Bazargan and Poldasht Plains Using Drastic Model Based on. GIS Journal of Environmental Science. 52; 64-55. [In Persian] 
Babiker, I.S. Mohamed, M.A. Hiyama, T. Kato, K.A. 2005. GIS-based DRASTIC model for assessing aquifer vulnerability in Kakamigahara, Heights, Gifu Prefecture, central Japan. Science of the Total Environment. 345 (1-3):127-140.

Baghapour, M.A. Fadaei Nobandegani, A. Talebbeydokhti, N. Bagherzadeh, S. Nadiri, A.A. Gharekhani, M., et al. 2016. Optimization of the DRASTIC method by an artificial neural network, nitrate vulnerability index, and composite DRASTIC models to assess groundwater vulnerability for unconfined aquifer of Shiraz Plain, Iran. Journal of Environmental Health Science and Engineering.

Barbulescu, A. 2020. Assessing Groundwater Vulnerability: DRASTIC and DRASTIC-Like Methods: A Review. Water. 12: 1356. doi:10.3390/w12051356

Barzegar, R. Asghari Moghadam, A. Nadiri, A.A. Fijani, E. 2014. Using Different Fuzzy Methods to Optimize Drastic Model in Assessing Aquifer Vulnerability, Case Study: Tabriz Plain Aquifer. Journal of Geology and Environment. 94: 211-222. [ In Persian]

Bhuvaneswaran, C. Ganesh, A. 2019. Spatial assessment of groundwater vulnerability using the DRASTIC model with GIS in Upper odai sub-watershed, Nandiyar, Cauvery Basin, Tamil Nadu. Groundwater for Sustainable Development. 9: 100270.

Busico, G. Kazakis, N. Cuoco, E. Colombani, Nicolo. Tedesco, D. Voudouris, K. Mastrocicco, M. 2020. A novel hybrid method of specific vulnerability to anthropogenic pollution using multivariate statistical and regression analyses. Water Res.

Calvo, P.I. Estrada, G.J.C. 2009. Improved irrigation water demand forecasting using a soft-computing hybrid model. Biosystems Engineering. 102(2): 202-218.

Chenini, I. Zghibi, A. Kouzana, L. 2015. Hydrogeological investigations and groundwater vulnerability assessment and mapping for groundwater resource protection and management: State of the art and a case study. J. Afr. Earth Sci. 109: 11-26.

Civita, M., 1994. Le Carte Della Vulnerabilit` a Degli Acquiferi All'inquinamento: Teoria \& Pratica [Aquifer Vulnerability to Pollution Maps: Theory and Practice]. Pitagora, Bologna, Italy.

Darvishzadeh, A. Geology of Iran. Amir Kabir Publishing Institute: Tehran; 2001. [ In Persian]

Foster, S.S.D. Ventura, M. Hirata, R.C. 1987. Contamination En America Latina Y El Caribe En Relation Con El Suministro De Agua Potable. OPS-CEPIS Informance T'ecnico, Lima, Pern.

Gogu, R.C. Dassargues, A. 2000. Current trends and future challenges in groundwater vulnerability assessment using overlay and index methods. Environmental Geology. 39:549-559.

https://doi.org/10.1016/j.watres.2019.115386. 
Jia, Z. Bian, J. Wang, Y. Wan, H. Sun, X. Li, Q. 2019. Assessment and validation of groundwater vulnerability to nitrate in porous aquifers based on a DRASTIC method modified by projection pursuit dynamic clustering model. Journal of Contaminant Hydrology. 226: 1022-1035.

Khan, M.M.A. Umar, R. Lateh, H. 2010. Assessment of aquifer vulnerability in parts of Indo Gangetic plain, India. Int. J. Phys. Sci. 5:1711-1720.

Margate, J. 1968. Vulnerability des nappes d'eausouterraine - la pollution (Groundwater vulnerability to contamination). Bases de la cartographie, (Doc). BRGM. 68 SGL 198 HYD. Orleans. France.

McLay, C.D.A. Dragten, R. Sparling, G. Selvarajah, N. 2001. Predicting groundwater nitrate concentrations in a region of mixed agricultural land use: a comparison of three approaches. Environmental Pollutants. 115:191-204.

Mendoza, J.A. Barmen, G. 2006. Assessment of groundwater vulnerability in the Rıo Artiguas basin, Nicaragua. Environ. Geol. 50: 569-580.

Nadiri, A.A. Gharekhani, M. Khatibi, R. 2018. Mapping Aquifer Vulnerability Indices using Artificial Intelligence-running Multiple Frameworks (AIMF) With Supervised and unsupervised learning. Water resource management. 3023-3040.

Nadiri, A.A. Gharekhani, M. Khatibi, R. Asghari Moghadam, A. 2017. Assessment of groundwater vulnerability using the supervising committee to combine fuzzy logic models. Environ Sci Pollut Res. DOI $10.1007 /$ s11356-017-8489-4

Piscopo, G. 2001. Groundwater vulnerability map, explanatory notes, Castlereagh Catchment, NSW. Department of Land and Water Conservation. Australia.

Qinghai, G. Yanxin, W. Xubo, G. Teng, M. 2007. A new model (DRARCH) for assessing groundwater vulnerability to arsenic contamination at basin scale: A case study in Taiyuan basin, northern China. Environ. Geol. 52: 923-932.

Rajasekaran, S. Pai, G.V. 2005. Neural Networks, Fuzzy Logic and Genetic Algorithms, Synthesis and, Applications; Prentice Hall of India Pvt. New Delhi. 226.

Rezaei, F. Safavi, H.R. Ahmadi, A. 2013. Groundwater vulnerability assessment using fuzzy logic: a case study in the Zayandehrood aquifers, Iran. Environmental Management. 51(1):267-277.

Ribeiro, L. 2000. SI: A New Index of Aquifer Susceptibility to Agricultural Pollution; ERSHA/CVRM, Instituto Superior Técnico: Lisboa, Portugal.

Sadeghfam, S. Hassanzadeh, Y. Nadiri, A.A. Zarghami, M. 2015. Localization of Groundwater Vulnerability Assessment Using Catastrophe Theory. Water Resour Manage. 30:4585-4601. 
Secunda, S. Collin, M.L. Melloul, A.J. 1998. Groundwater vulnerability assessment using a composite model combining DRASTIC with extensive agricultural land use in Israel's Sharon region. Journal of Environmental Management. 54:39-57.

Singh, A. Srivastav, S.K. Kumar, S. Chakrapani, G.J. 2015. A modified-DRASTIC model (DRASTICA) for assessment of groundwater vulnerability to pollution in an urbanized environment in Lucknow, India. Environ. Earth Sci. 74: 5475-5490.

Singh, B. Singh, Y. Sekhon, GS. 1995. Fertilizer-N use efficiency and nitrate pollution of groundwater in developing countries. Journal of Contaminant Hydrology. 20 (3-4): 167-184.

Stempvoort, D.V. Ewert, L. Wassenaar, L. 1993. Aquifer Vulnerability Index: a GIS compatible method for groundwater vulnerability mapping. Can. Water Resour. J. 18 (1).

Sugeno, M. 1985. Industrial applications of fuzzy control, Elsevier Science Inc.

Tayfur, G. Nadiri, A.A, Asghari Moghadam, A. 2014. Supervised Intelligent Committee Mechin Method for Hydraulic Conductivity Estimation. Water Resources Management. 28: 1173-1184.

Tuinhof, A. Foster, S. Steenbergen, F. Talbi, A. Wishart, M. 2011. Sustainable groundwater management contributions to policy promotion appropriate groundwater management policy for Sub Saharan Africa.

Vrba, J. Zeporozec, A. 1995. Guidebook on mapping groundwater vulnerability. International Contribution to Hydrogeology. 16. 131.

Wang, Y. Merkel, B.J. Li, Y. Ye, H. Fu, S.. Ihm, D., 2007. Vulnerability of groundwater in Quaternary aquifers to organic contaminants: A case study in Wuhan City, China. Environ. Geol. 53: 479-484.

Zadeh LA. 1965. Fuzzy sets. Information and Control. 8: 338-353.

Zhou, J. Li, G. Liu, F. Wang, Y. Guo, X. 2010. DRAV model and its application in assessing groundwater vulnerability in arid area: A case study of pore phreatic water in Tarim Basin, Xinjiang, Northwest China. Environ. Earth Sci. 60: 1055-1063.

\section{Figures}




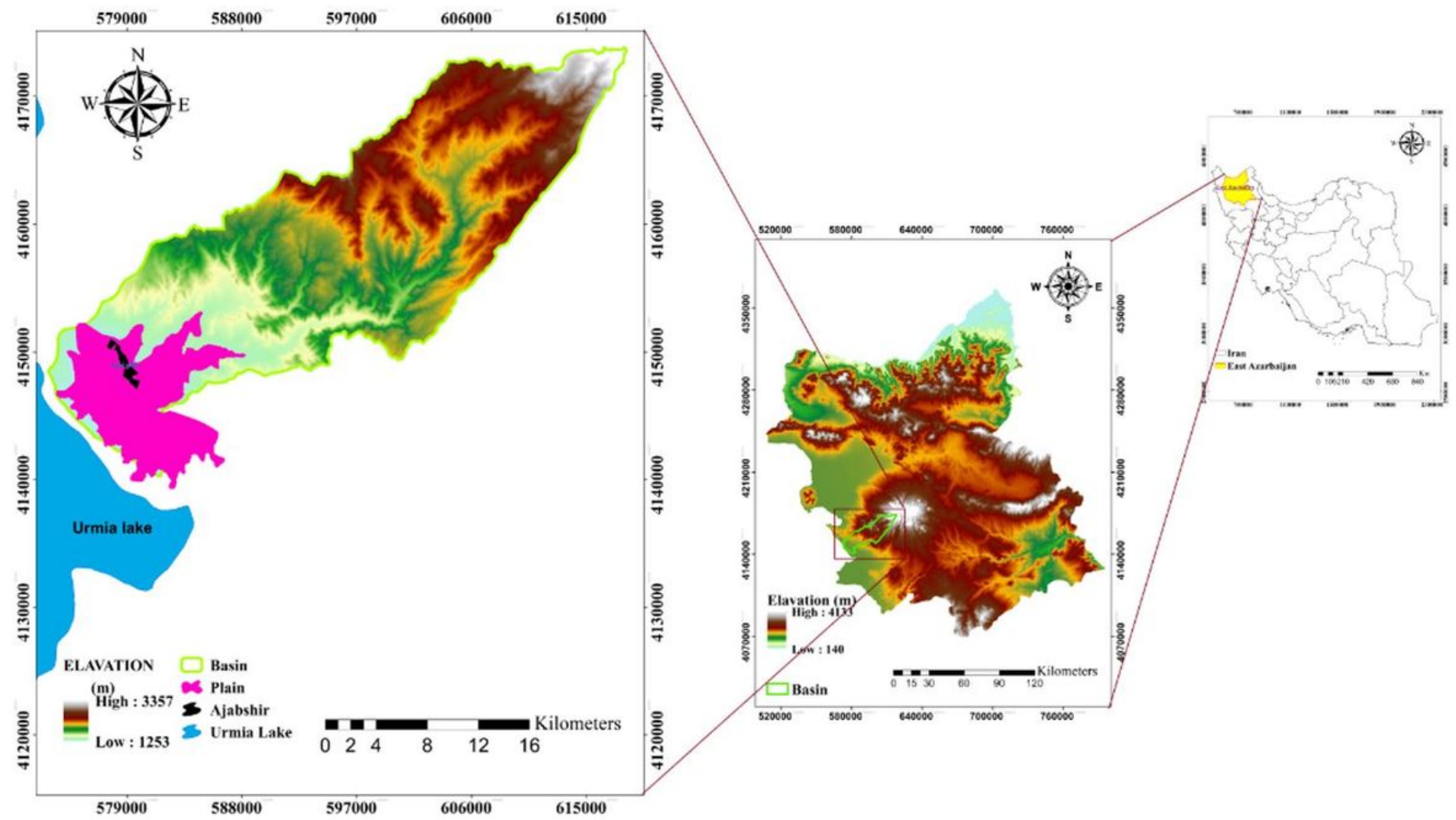

Figure 1

The digital elevation model and location of the study area 


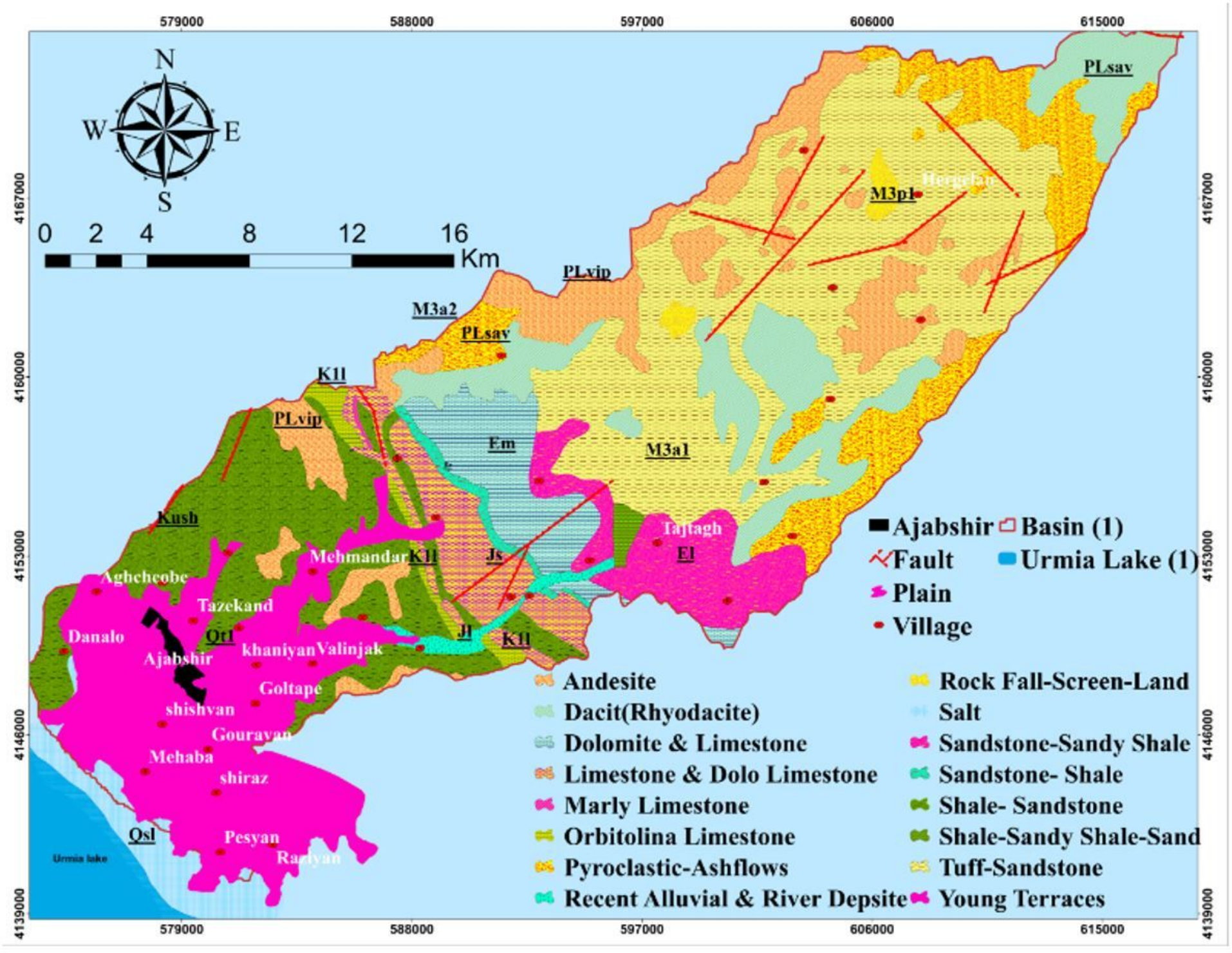

Figure 2

Geological map of the study area 

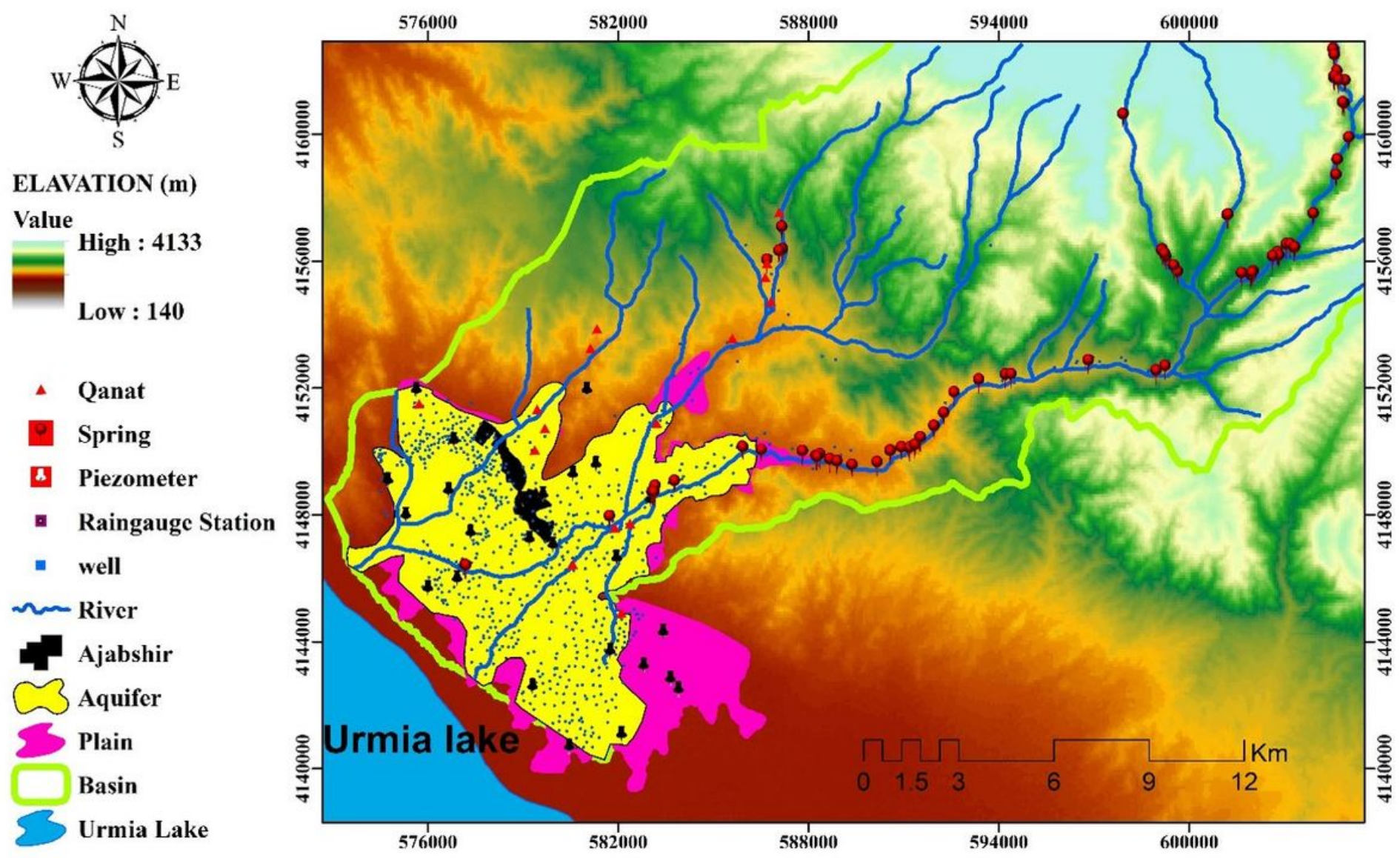

\section{Figure 3}

Digital elevation model and groundwater resources map of the study area

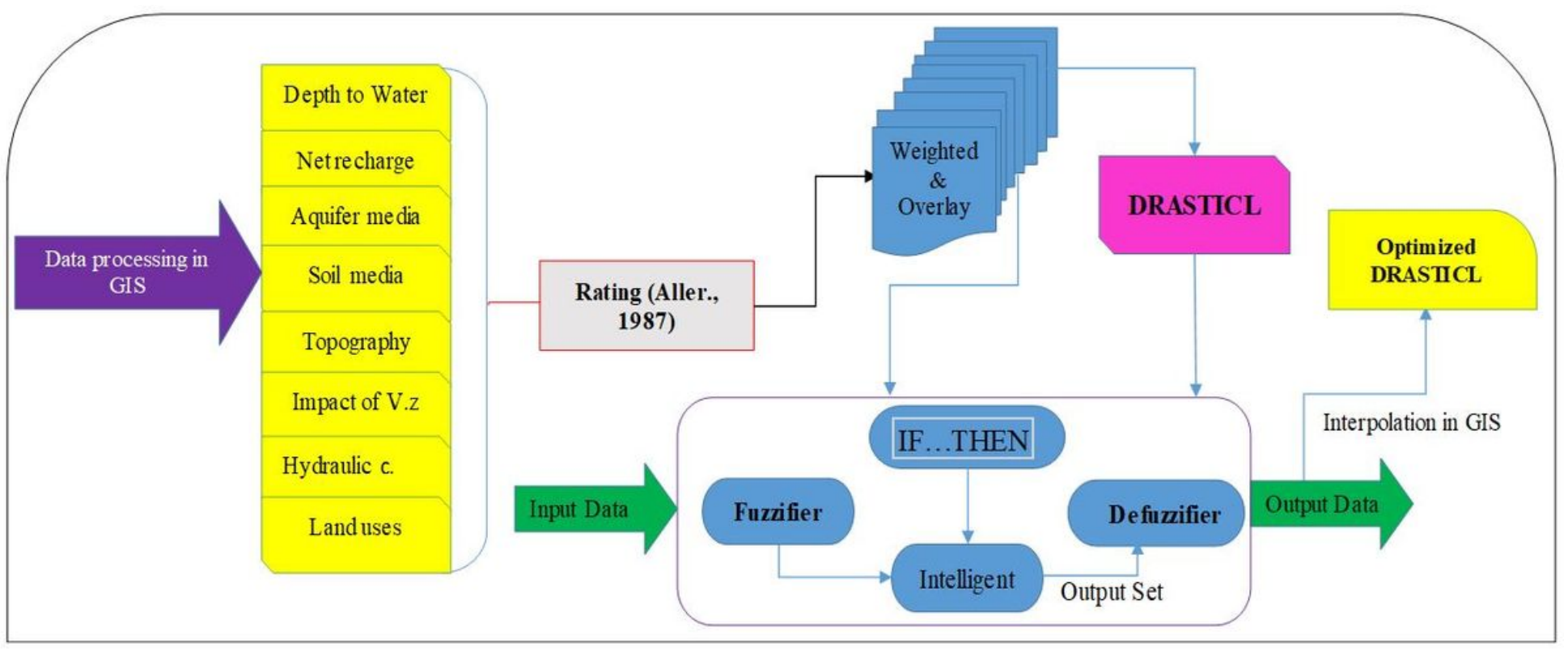

Figure 4

The flowchart of the methodology used in this study 

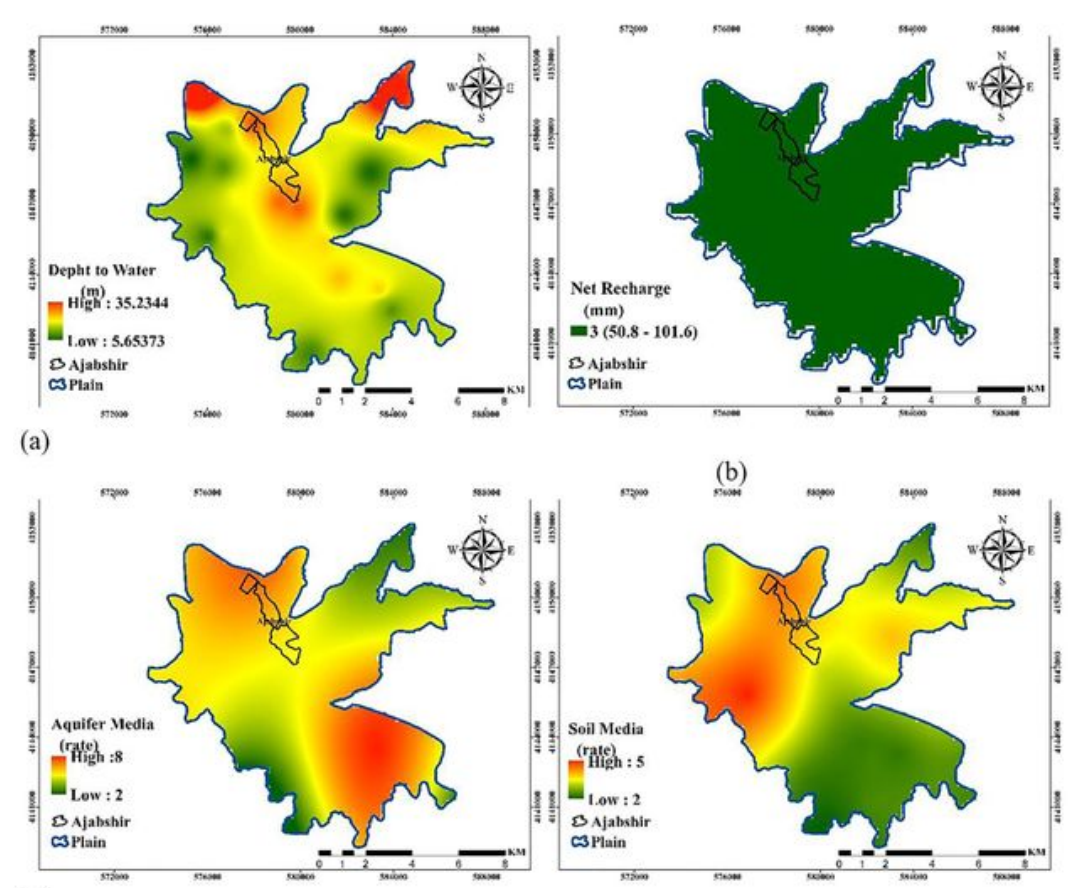

(c)

(d)
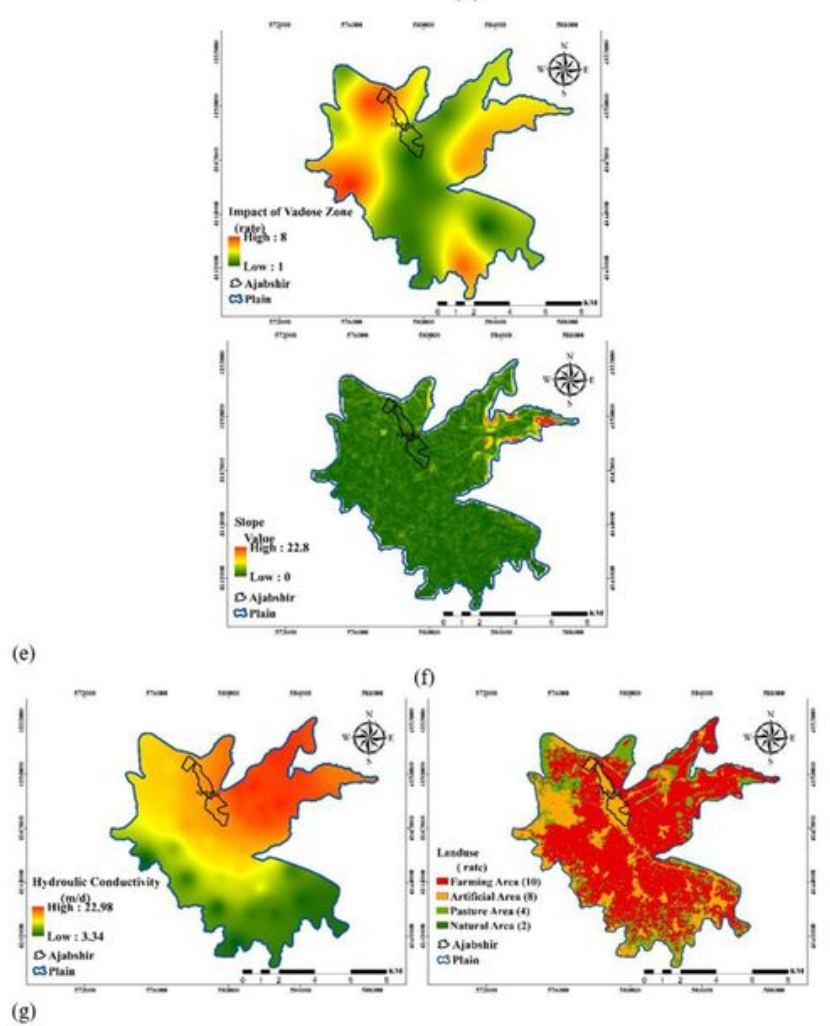

Figure 5

Layers of the DRASTICL framework, (a) groundwater depth, (b) net recharge, (c) aquifer media, (d) soil media, (e) impact of vadose zone, (f) topography, (f) hydraulic conductivity and (h) land-use layer 


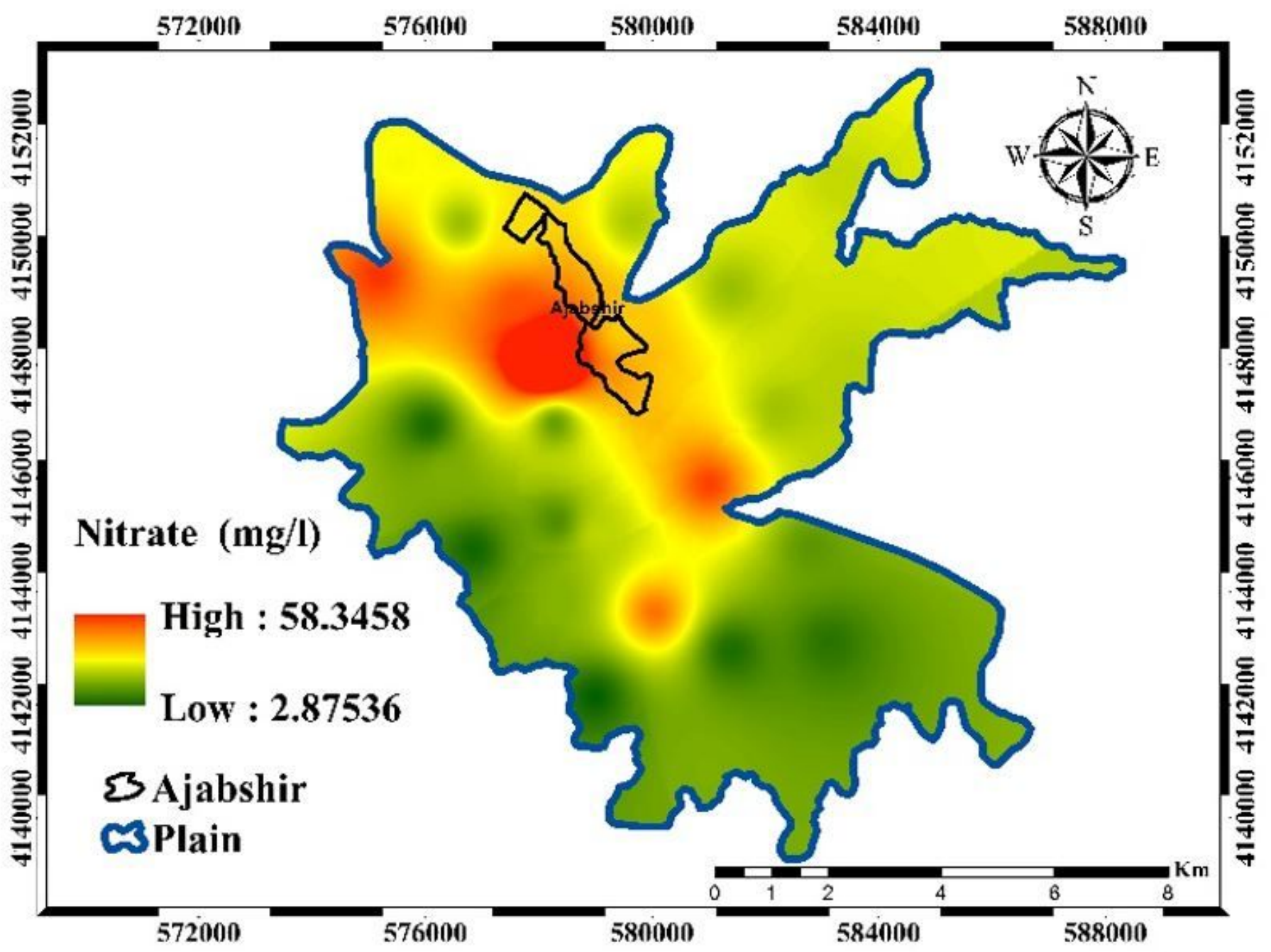

Figure 6

Nitrate concentration map in the Ajabshir plain 


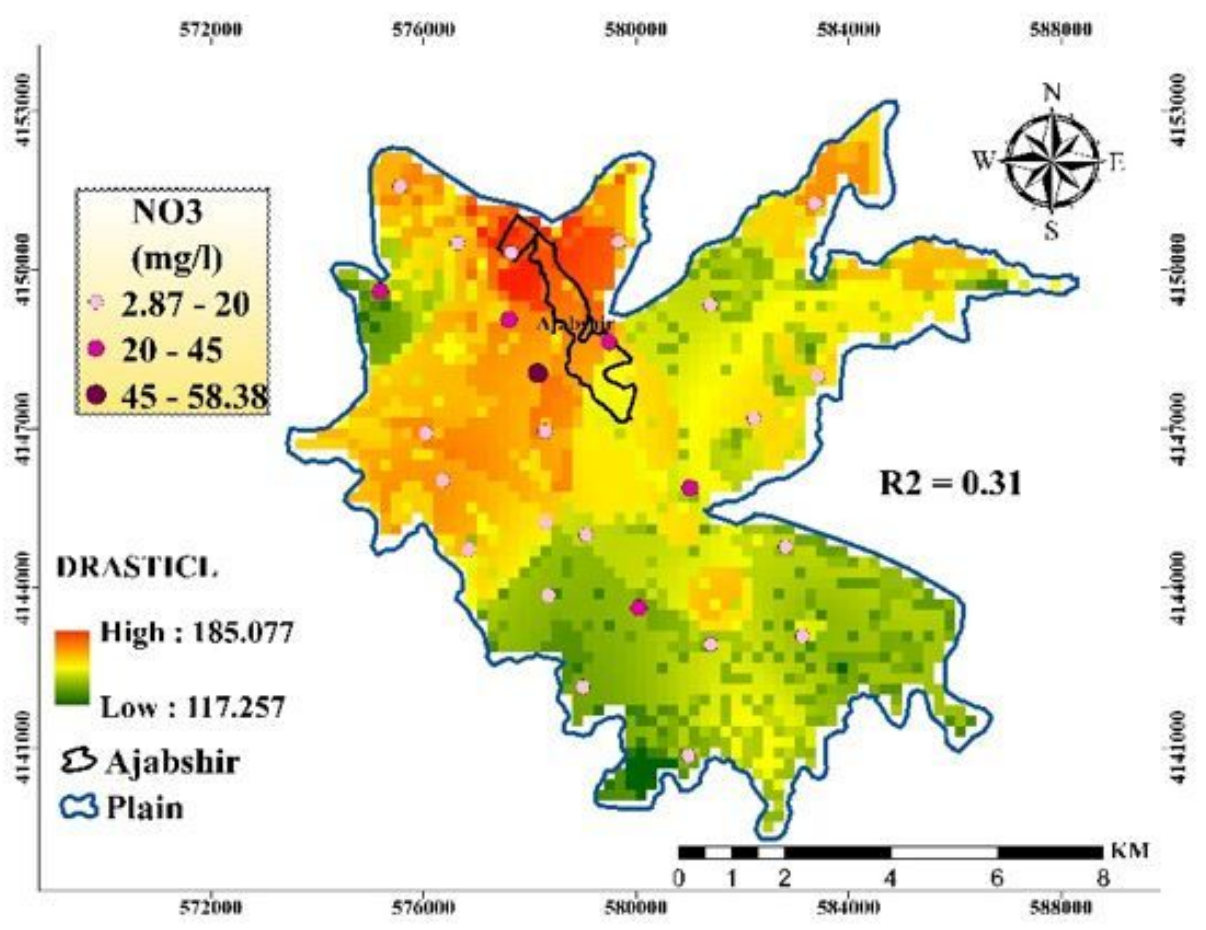

(a)

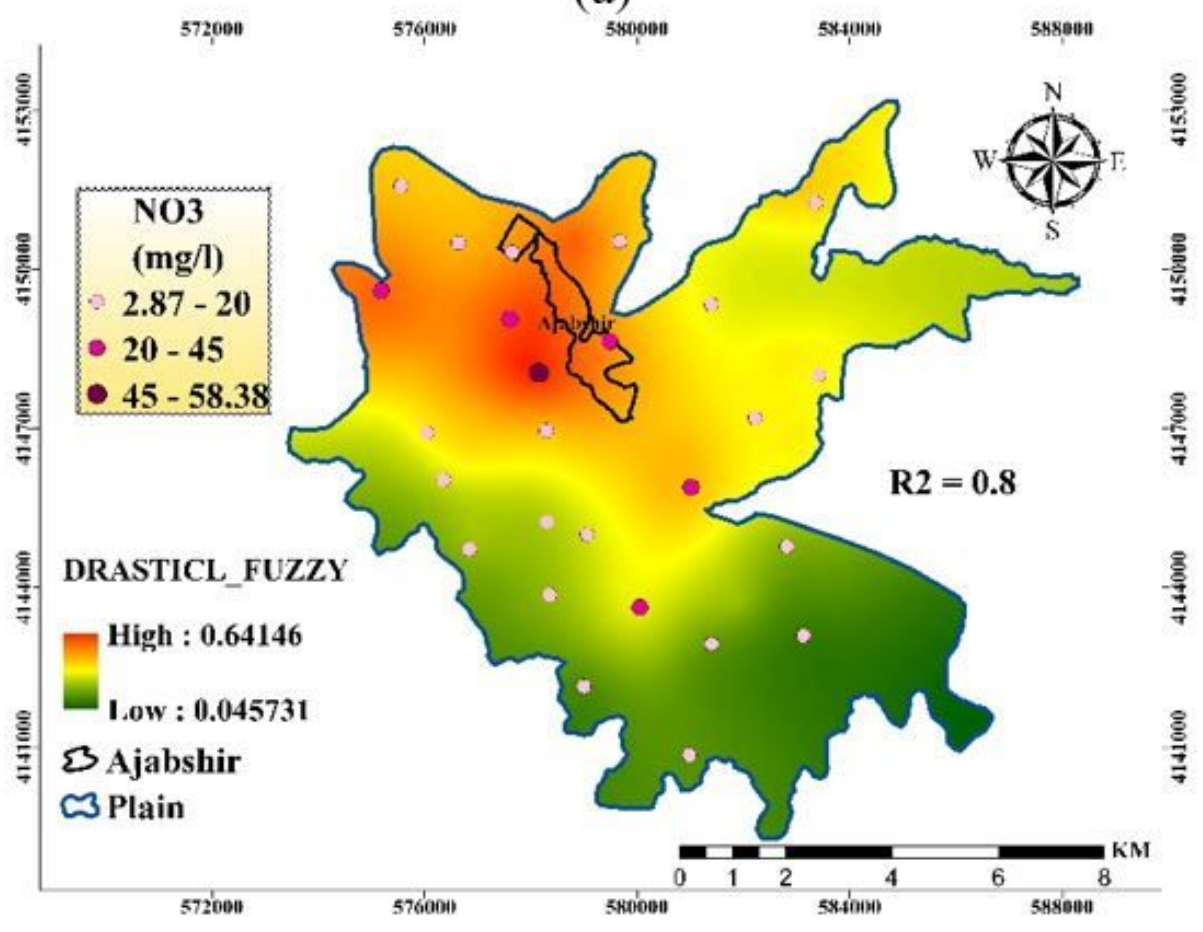

(b)

Figure 7

Zoning of Vulnerability Maps of the Ajabshir Plain, a) DRASTICL b) Optimized DRASTICL by Fuzzy 